\title{
BMJ
}

\section{Use of smokeless tobacco and risk of myocardial infarction and stroke: systematic review with meta-analysis}

\author{
Paolo Boffetta, epidemiologist Kurt Straif, epidemiologist
}

\begin{abstract}
International Agency for Research on Cancer, Lyon, France

Correspondence to: P Boffetta, Genetics and Epidemiology Cluster, International Agency for Research on Cancer, 150 Cours Albert Thomas, 69008 Lyon, France boffetta@iarc.fr

Cite this as: $B M J$ 2009;339:b3060 doi:10.1136/bmj.b3060
\end{abstract}

\author{
ABSTRACT \\ Objective To assess whether people who use smokeless \\ tobacco products are at increased risk of myocardial \\ infarction and stroke. \\ Design Meta-analysis of observational studies from \\ Sweden and the United States.
}

Data sources Electronic databases and reference lists. Data extraction Quantitative estimates of the association between use of smokeless tobacco products and risk of myocardial infarction and stroke among never smokers.

Review methods Both authors independently abstracted risk estimates and study characteristics. Summary relative risks were estimated on the basis of random effects models.

Results 11 studies, mainly in men, were included. Eight risk estimates were available for fatal myocardial infarction: the relative risk for ever use of smokeless tobacco products was 1.13 (95\% confidence 1.06 to 1.21) and the excess risk was restricted to current users. The relative risk of fatal stroke, on the basis of five risk estimates, was 1.40 (1.28 to 1.54). The studies from both the United States and Sweden showed an increased risk of death from myocardial infarction and stroke. The inclusion of non-fatal myocardial infarction and non-fatal stroke lowered the summary risk estimates. Data on doseresponse were limited but did not suggest a strong relation between risk of dying from either disease and frequency or duration of use of smokeless tobacco products.

Conclusion An association was detected between use of smokeless tobacco products and risk of fatal myocardial infarction and stroke, which does not seem to be explained by chance.

\section{INTRODUCTION}

Oral and nasal smokeless tobacco products have been used in many countries for centuries. During most of the 20th century, use of these products declined in Europe and North America, but a reverse trend in prevalence of use has been reported in the past few decades, particularly among people younger than $40 .{ }^{1}$ These products have been proposed as an alternative to cigarettes and other smoking products under the claim of a smaller, or negligible, risk to health. ${ }^{2}$ Smokeless tobacco is a recognised carcinogen in humans ${ }^{1}$; other potential health effects include an increased risk of myocardial infarction, stroke, and adverse reproductive outcome. ${ }^{134}$ Determining the role of smokeless tobacco in cardiovascular diseases is important, given the high incidence and mortality from these diseases.

We systematically reviewed studies that analysed the risk of myocardial infarction and stroke among users of smokeless tobacco products, with the aim of updating and expanding a previous review and metaanalysis on this topic. ${ }^{5}$ Smokeless tobacco products consumed in Asia are different from those consumed in Europe and North America. We aimed to determine whether users of smokeless tobacco products in Sweden and North America are at an increased risk of death from myocardial infarction and from stroke compared with non-users.

\section{METHODS}

The MOOSE guidelines for meta-analysis of observational studies in epidemiology were followed. ${ }^{6} \mathrm{We}$ selected studies that provided a quantitative estimate of the association between ever use of smokeless tobacco products and occurrence (incidence or mortality) of myocardial infarction or stroke among never smokers. We carried out a search in PubMed using the terms (“"cardiovascular diseases"[MeSH Terms] OR ("cardiovascular"[All Fields] AND "diseases"[All Fields]) OR "cardiovascular diseases"[All Fields]) OR ("cerebrovascular disorders"[MeSH Terms] OR ("cerebrovascular"[All Fields] AND "disorders"[All Fields]) OR "cerebrovascular disorders"[All Fields] OR MORTALITY OR DEATH*)) AND ((((((snus)) OR ((snuff))) OR ((tobacco, smokeless[mesh]))) OR ((“smokeless tobacco"))) OR ((“spit tobacco" OR "chewing tobacco"))) AND ((cohort studies[mesh] OR case control studies[mesh]) OR (cohort[TI] AND stud*[TI]) OR (case*[TI] AND control*[TI] OR prospective study)), which identified 118 potentially relevant references. We completed it with a second search in ISI Web of Science 1945-2009 (updated 15 January 2009) using the terms ((Snus OR snuff OR OR "spit* tobacco" OR "smokeless tobacco" OR "tobacco SAME smokeless" OR "chewing tobacco" OR "tobacco SAME chewing") AND (cardiovascular OR cerebrovascular OR "heart" OR "myocardial infarction" OR mortality OR death* OR ischaemic OR ischemic OR stroke OR coronary) AND (Cohort* 
OR Case* OR control* OR prospective)), which resulted in an additional 75 references. After excluding irrelevant studies ${ }^{\mathrm{w1}-\mathrm{w} 175}$ we checked the reference lists of relevant studies and identified one additional publication. ${ }^{\text {w176 }}$ After further exclusion of studies done in Asia $^{\text {w177-w181 }}$ (including one study carried out in 52 countries, predominantly Asian ${ }^{\mathrm{w} 181}$ ), reports in subsequent publications, ${ }^{\text {w176 w182 w183 }}$ and studies not reporting separate risk estimates for myocardial infarction and stroke, ${ }^{\text {w184 }} 10$ publications were included for metaanalysis. $^{7-16}$

\section{Data extraction and quality assessment}

Both authors independently abstracted the estimates of risk of cardiovascular diseases, ischaemic heart disease or myocardial infarction, and cerebrovascular disease or stroke (including separate estimates for the fatal forms of the diseases, if available) and the characteristics of the study. The abstracted data were compared and any inconsistencies resolved. When possible, risk estimates for current and former use of smokeless tobacco were abstracted separately.

If several risk estimates were available from one study (for example, separate results for men and women or for current and former use), we combined them by carrying out a meta-analysis based on a fixed effect model.

\section{Data synthesis and analysis}

We carried out a meta-analysis of the study specific results based on a random effects model. ${ }^{17}$ We used the statistical package STATA to test for heterogeneity and to calculate summary relative risks and $95 \%$ confidence intervals. ${ }^{18}$ Begg's test was used to determine the presence of publication bias. ${ }^{19}$

We classified studies on the basis of outcome (myocardial infarction, stroke), country (United States, Sweden), study design (cohort, including nested casecontrol, other case-control), and adjustment for potential confounders, in addition to age and sex. We repeated the meta-analysis after stratification by country (United States, Sweden). As is usual in main analyses of epidemiological studies, ${ }^{20}$ we combined the results of cohort and case-control studies. The possible influence of study design was assessed by repeating the main analysis with cohort studies only. Three case-control studies were available: all were from Sweden and reported only results on myocardial infarction. To disentangle the effect of country from that of study design we carried out a further meta-analysis of myocardial infarction restricted to cohort studies from Sweden.

\section{Calculation of attributable fraction}

The attributable fraction is a measure of the burden of smokeless tobacco use on cardiovascular diseases. It can be estimated on the basis of the relative risk from use of smokeless tobacco and the proportion of the exposed population: proportion of exposed population $\times($ relative risk -1$)$ divided by [proportion of exposed population $\times($ relative risk -1$)]+1$.
We used the country specific relative risk of fatal myocardial infarction and fatal stroke derived from the present meta-analysis, and data on proportion of smokeless tobacco users from surveys in the United States $^{21}$ and Sweden. ${ }^{22}$

\section{RESULTS}

Eleven studies reported in 10 publications were included in the meta-analysis (fig 1 and table 1). ${ }^{7-16}$ Eight studies were from Sweden and three from the United States. Eight studies used a prospective cohort design (in two, only results based on nested case-control analyses were reported) and three used a population based case-control design. Nine studies were restricted to never tobacco smokers, whereas two also included former smokers. ${ }^{78}$ Fixed effect meta-analyses of stratified results were done for four studies to obtain a summary relative risk. ${ }^{9111215}$

The nine independent risk estimates for myocardial infarction (table 1) resulted in a summary relative risk for ever use of smokeless tobacco products of 0.99 (95\% confidence interval 0.89 to 1.10 ), with evidence of heterogeneity between studies (table 2; test for publication bias $\mathrm{P}=0.2$ ). No evidence of an increased risk was present among current users (seven risk estimates, with heterogeneity) or former users (four risk estimates; table 2). Restricting the meta-analysis to cohort studies gave a summary relative risk of 1.04 (0.95 to 1.14 , six risk estimates). As all studies but one were in men, the analyses stratified by sex were not informative.

No heterogeneity was found among the studies reporting fatal myocardial infarction, resulting in a summary relative risk for ever use of 1.13 (1.06 to 1.21 ), based on eight risk estimates (table 2, fig 2; test for publication bias $\mathrm{P}=0.4$ ). The increase was present for current use of smokeless tobacco products but not

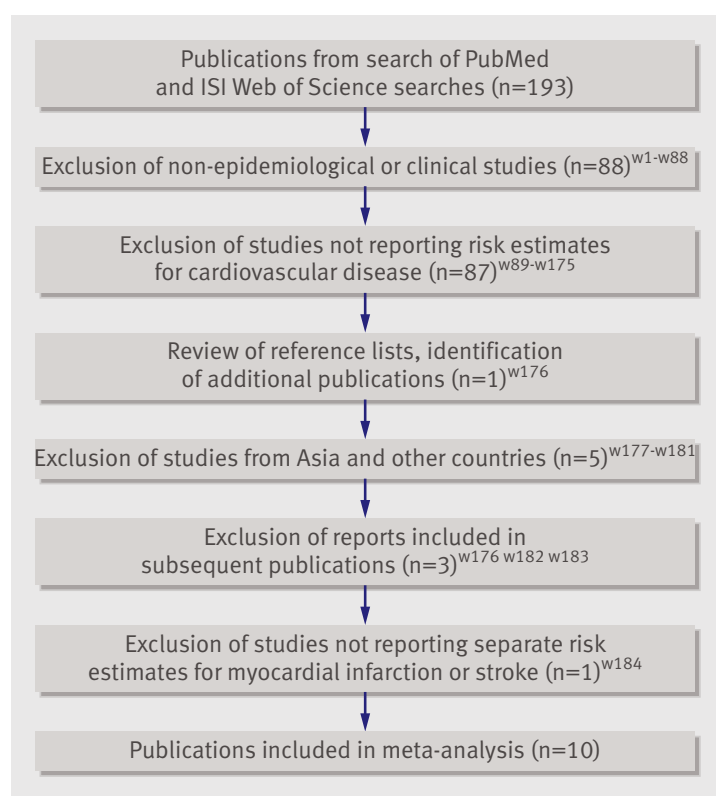

Fig 1| Strategy for selection of studies in meta-analysis 
Table 1|Epidemiological studies on use of smokeless tobacco and risk of cardiovascular disease included in meta-analysis

\begin{tabular}{|c|c|c|c|c|c|c|c|c|}
\hline Reference & $\begin{array}{l}\text { Country, sex, } \\
\text { recruitment, follow- } \\
\text { up }\end{array}$ & $\begin{array}{l}\text { Study } \\
\text { design }\end{array}$ & Adjustment factors & Exposure & Outcome & $\begin{array}{l}\text { No of cases/ } \\
\text { No of deaths }\end{array}$ & Relative risk $(95 \% \mathrm{Cl})$ & Comments \\
\hline $\begin{array}{l}\text { Huhtasaari etal } \\
1992^{7}\end{array}$ & $\begin{array}{l}\text { Sweden, men, 1989- } \\
91, \text { NR }\end{array}$ & $\begin{array}{l}\text { Population } \\
\text { based case- } \\
\text { control }\end{array}$ & Age, region of residence & Snuff & Myocardial infarction & 177 & 0.89 (0.62 to 1.29$)$ & $\begin{array}{l}\text { Including former } \\
\text { smokers; limited overlap } \\
\text { with Wennberg et al } \\
2007^{15}\end{array}$ \\
\hline $\begin{array}{l}\text { Huhtasaari et al } \\
1999^{8}\end{array}$ & $\begin{array}{l}\text { Sweden, men, 1991-3, } \\
\text { NR }\end{array}$ & $\begin{array}{l}\text { Population } \\
\text { based case- } \\
\text { control }\end{array}$ & $\begin{array}{l}\text { Age, region of } \\
\text { residence, "various } \\
\text { cardiovascular risk } \\
\text { factors" }\end{array}$ & Snuff & $\begin{array}{l}\text { Fatal myocardial } \\
\text { infarction }\end{array}$ & NA/NA & $\begin{array}{l}0.58(0.35 \text { to } 0.94), \\
1.50(0.45 \text { to } 5.03)\end{array}$ & $\begin{array}{l}\text { Including former } \\
\text { smokers; limited overlap } \\
\text { with Hergens et al } 2005^{12} \\
\text { and Wennberg et al } \\
2007^{15}\end{array}$ \\
\hline $\begin{array}{l}\text { Accortt et al } \\
2002^{9}\end{array}$ & $\begin{array}{l}\text { United States, both } \\
\text { sexes, 1971-5, 1971- } \\
92\end{array}$ & Cohort & $\begin{array}{l}\text { Age, sex, } \\
\text { socioeconomic status, } \\
\text { alcohol consumption, } \\
\text { physical activity, fruit } \\
\text { and vegetable intake, } \\
\text { blood pressure, } \\
\text { cholesterol, body mass } \\
\text { index }\end{array}$ & $\begin{array}{l}\text { Smokeless } \\
\text { tobacco }\end{array}$ & $\begin{array}{l}\text { Fatal myocardial } \\
\text { infarction, fatal stroke }\end{array}$ & NA/NA & $\begin{array}{l}1.0(0.7 \text { to } 1.6)^{\star}, 0.8 \\
(0.4 \text { to } 1.8)^{\star}\end{array}$ & $\begin{array}{l}\text { Proxy interviews for } \\
\text { many; meta-analysis of } \\
\text { results reported in paper } \\
\text { (sex) }\end{array}$ \\
\hline
\end{tabular}

\begin{tabular}{|c|c|c|c|c|c|c|c|}
\hline $\begin{array}{l}\text { Asplund et al } \\
2003^{10}\end{array}$ & $\begin{array}{l}\text { Sweden, men,1985-6, } \\
1985-2000\end{array}$ & $\begin{array}{l}\text { Case-control } \\
\text { analysis } \\
\text { nested in } \\
\text { cohort study }\end{array}$ & $\begin{array}{l}\text { Age, region of } \\
\text { residence, education, } \\
\text { blood pressure, } \\
\text { diabetes, cholesterol, } \\
\text { marital status }\end{array}$ & Snuff & Stroke & NA & 1.05 (0.37 to 2.94$)$ \\
\hline $\begin{array}{l}\text { Henley et al } \\
2005^{11}\end{array}$ & $\begin{array}{l}\text { United States, men, } \\
1959,1959-71\end{array}$ & Cohort & $\begin{array}{l}\text { Age, race, education, } \\
\text { alcohol consumption, }\end{array}$ & $\begin{array}{l}\text { Spit } \\
\text { tobacco }\end{array}$ & $\begin{array}{l}\text { Fatal myocardial } \\
\text { infarction, fatal stroke }\end{array}$ & $799 / 460$ & $\begin{array}{l}1.12(1.03 \text { to } 1.21), \\
1.46(1.31 \text { to } 1.64)\end{array}$ \\
\hline
\end{tabular}
physical activity, aspirin intake, body mass index, fruit and vegetable intake

\begin{tabular}{|c|c|c|c|c|c|c|c|c|}
\hline $\begin{array}{l}\text { Henley et al } \\
2005^{11}\end{array}$ & $\begin{array}{l}\text { United States, men, } \\
1982,1982-8\end{array}$ & Cohort & $\begin{array}{l}\text { Age, race, education, } \\
\text { alcohol consumption, } \\
\text { physical activity, }\end{array}$ & $\begin{array}{l}\text { Spit } \\
\text { tobacco }\end{array}$ & $\begin{array}{l}\text { Fatal myocardial } \\
\text { infarction, fatal stroke }\end{array}$ & $216 / 100$ & $\begin{array}{l}1.11(0.97 \text { to } 1.28)^{\star} \\
1.34(1.09 \text { to } 1.65)^{\star}\end{array}$ & $\begin{array}{l}\text { Meta-analysis of results } \\
\text { reported in paper (current } \\
\text { or former use) }\end{array}$ \\
\hline
\end{tabular}
or former use)

aspirin intake, body

vegetable intake,

occupation

\begin{tabular}{|c|c|c|c|c|c|c|c|c|}
\hline $\begin{array}{l}\text { Hergens et al } \\
2005^{12}\end{array}$ & $\begin{array}{l}\text { Sweden, men, 1992-4, } \\
\text { NR }\end{array}$ & $\begin{array}{l}\text { Population } \\
\text { based case- } \\
\text { control }\end{array}$ & Age, region of residence & Snuff & $\begin{array}{l}\text { Fatal myocardial } \\
\text { infarction }\end{array}$ & $310 / 49$ & $\begin{array}{l}0.88\left(0.49 \text { to } 1.60^{\star}, 1.7\right. \\
(0.59 \text { to } 4.9)^{\star}\end{array}$ & $\begin{array}{l}\text { Meta-analysis of results } \\
\text { reported in paper (current } \\
\text { or former use); limited } \\
\text { overlap with Huhtasaari } \\
\text { et al } 1999^{8}\end{array}$ \\
\hline
\end{tabular}

Haglund et al Sweden, men, 1988-9, Cohort

Age, region of

residence,

socioeconomic status,

physical activity, self

Snuff

Fatal myocardial

255/72; $145 / 0.77$ (0.51 to 1.15$)$,

reported health,

number of chronic

diseases

\begin{tabular}{|c|c|c|c|c|c|c|c|c|}
\hline $\begin{array}{l}\text { Hergens et al } \\
2007^{14}\end{array}$ & $\begin{array}{l}\text { Sweden, men, 1978- } \\
\text { 93, 1978-2004 }\end{array}$ & Cohort & $\begin{array}{l}\text { Age, place of residence, } \\
\text { body mass index }\end{array}$ & Snuff & $\begin{array}{l}\text { Fatal myocardial } \\
\text { infarction }\end{array}$ & $3651 / 841$ & $\begin{array}{l}0.99 \text { (0.90 to } 1.10), \\
1.28(1.06 \text { to } 1.55)\end{array}$ & $\begin{array}{l}\text { Same cohort as for } \\
\text { Hergens et al } 2008^{16}\end{array}$ \\
\hline $\begin{array}{l}\text { Wennberg et al } \\
2007^{15}\end{array}$ & $\begin{array}{l}\text { Sweden, men, 1985-6, } \\
1985-99\end{array}$ & $\begin{array}{l}\text { Case-control } \\
\text { analysis } \\
\text { nested in } \\
\text { cohort study }\end{array}$ & $\begin{array}{l}\text { Age, education, } \\
\text { physical activity, body } \\
\text { mass index, cholesterol }\end{array}$ & Snuff & $\begin{array}{l}\text { Fatal myocardial } \\
\text { infarction }\end{array}$ & $843 / 39$ & $\begin{array}{l}0.75(0.48 \text { to } 1.18)^{\star} \\
0.94(0.38 \text { to } 2.30)^{\star}\end{array}$ & $\begin{array}{l}\text { Meta-analysis of results } \\
\text { reported in paper (current } \\
\text { or former use); limited } \\
\text { overlap with Huhtasaari } \\
\text { et al } 2002^{78}\end{array}$ \\
\hline $\begin{array}{l}\text { Hergens et al } \\
2008^{16}\end{array}$ & $\begin{array}{l}\text { Sweden, men, 1978- } \\
93,1978-2003\end{array}$ & Cohort & $\begin{array}{l}\text { Age, place of residence, } \\
\text { body mass index }\end{array}$ & Snuff & Stroke, fatal stroke & $444 / 45$ & $\begin{array}{l}1.02(0.92 \text { to } 1.13), \\
1.27(0.92 \text { to } 1.76)\end{array}$ & $\begin{array}{l}\text { Same cohort as for } \\
\text { Hergens et al } 2007^{14}\end{array}$ \\
\hline
\end{tabular}

$\mathrm{NA}=$ not available; $\mathrm{NR}=$ not relevant.

${ }^{\star}$ Results of meta-analysis. for former use. An increased risk of fatal myocardial infarction was present in studies from both the United States and Sweden. In one study from the United States, which analysed chewing tobacco and snuff use separately, the results were similar. ${ }^{11}$ Restricting the analysis to the three risk estimates from cohort studies in Sweden gave a summary relative risk of 1.26 (1.05 to 1.51). Dose-response analyses for fatal myocardial infarction were reported in two studies ${ }^{1114}$ : in neither was there a significant trend in risk by duration or frequency of use, but in one study the relative risk of fatal myocardial infarction was highest in the group that used smokeless tobacco most often. ${ }^{14}$

On the basis of six risk estimates the overall relative risk of stroke was 1.19 (0.97 to 1.47 ; test for publication bias $\mathrm{P}=1.0$; table 2). The results were heterogeneous. 
Table 2 Results of meta-analysis on risk of myocardial infarction and stroke* and use of smokeless tobacco products

\begin{tabular}{|c|c|c|c|}
\hline Outcome and subgroups & $\begin{array}{l}\text { No of risk } \\
\text { estimates }\end{array}$ & $\begin{array}{c}\mathrm{P} \text { for } \\
\text { heterogeneity }\end{array}$ & $\begin{array}{l}\text { Relative risk } \\
(95 \% \mathrm{Cl})\end{array}$ \\
\hline \multicolumn{4}{|l|}{ Any myocardial infarction: } \\
\hline Overall & 9 & 0.05 & 0.99 (0.89 to 1.10$)$ \\
\hline Current use of smokeless tobacco & 7 & 0.02 & 1.03 (0.91 to 1.17$)$ \\
\hline Former use of smokeless tobacco & 4 & 0.7 & 0.74 (0.60 to 0.91$)$ \\
\hline Cohort studies & 6 & 0.1 & 1.04 (0.95 to 1.14$)$ \\
\hline United States & 3 & 0.9 & 1.11 (1.04 to 1.19$)$ \\
\hline Sweden & 6 & 0.01 & 0.87 (0.75 to 1.02$)$ \\
\hline Sweden—cohort studies & 3 & 0.3 & 0.92 (0.77 to 1.09$)$ \\
\hline \multicolumn{4}{|l|}{ Fatal myocardial infarction: } \\
\hline Overall & 8 & 0.9 & 1.13 (1.06 to 1.21$)$ \\
\hline Current use of smokeless tobacco & 6 & 0.6 & 1.17 (1.09 to 1.25$)$ \\
\hline Former use of smokeless tobacco & 4 & 0.6 & $0.76(0.58$ to 0.99$)$ \\
\hline Cohort studies & 6 & 0.8 & 1.13 (1.06 to 1.21$)$ \\
\hline United States & 3 & 0.9 & 1.11 (1.04 to 1.19$)$ \\
\hline Sweden & 5 & 0.9 & 1.27 (1.07 to 1.52$)$ \\
\hline Sweden—cohort studies & 3 & 0.8 & $1.26(1.05$ to 1.51$)$ \\
\hline \multicolumn{4}{|l|}{ Any stroke: } \\
\hline Overall & 6 & $<0.001$ & 1.19 (0.97 to 1.47$)$ \\
\hline Current use of smokeless tobacco & 3 & $<0.001$ & 1.28 (1.00 to 1.64$)$ \\
\hline Former use of smokeless tobacco & 2 & 0.05 & $0.93(0.56$ to 1.55$)$ \\
\hline United States & 3 & 0.3 & $1.39(1.22$ to 1.60$)$ \\
\hline Sweden & 3 & 1.0 & 1.02 (0.93 to 1.13$)$ \\
\hline \multicolumn{4}{|l|}{ Fatal stroke: } \\
\hline Overall & 5 & 0.5 & $1.40(1.28$ to 1.54$)$ \\
\hline Current use of smokeless tobacco & 3 & 0.9 & 1.44 (1.31 to 1.59$)$ \\
\hline Former use of smokeless tobacco & 2 & 0.2 & 0.86 (0.26 to 2.79$)$ \\
\hline United States & 3 & 0.3 & 1.39 (1.22 to 1.60$)$ \\
\hline Sweden & 2 & 0.7 & 1.25 (0.91 to 1.70$)$ \\
\hline
\end{tabular}

*All studies included in meta-analysis were of cohort design.

As was the case with myocardial infarction, all studies but one included only men and therefore stratification of the meta-analysis by sex was not informative. Only three estimates were available for current use of smokeless tobacco products and two estimated for former use: an increased risk was present only for current exposure. Studies from Sweden (three risk estimates) showed no increased risk of stroke. The results on fatal stroke were not heterogeneous. The overall relative risk on the basis of five risk estimates was $1.40(1.28$ to 1.54 , table 2 and fig 3 ; test for publication bias $\mathrm{P}=0.2$ ). Results were comparable between studies from the United States and Sweden (three risk estimates compared with two risk estimates, respectively). In the only study that reported results according to frequency or duration of use, no significant trend in the risk of fatal stroke was detected for either dimension of use, but the relative risk was highest in the group with longest duration of use. ${ }^{11}$ Only one of the studies reported results by type of stroke among snuff users: the relative risk for fatal ischaemic stroke $(1.63,1.02$ to 2.62) was higher than that for haemorrhagic stroke $(1.05,0.61$ to 1.80 ; test for heterogeneity $\mathrm{P}=0.2) .{ }^{16}$

The results of the calculation of attributable fraction are presented in table 3 . The proportion of deaths from

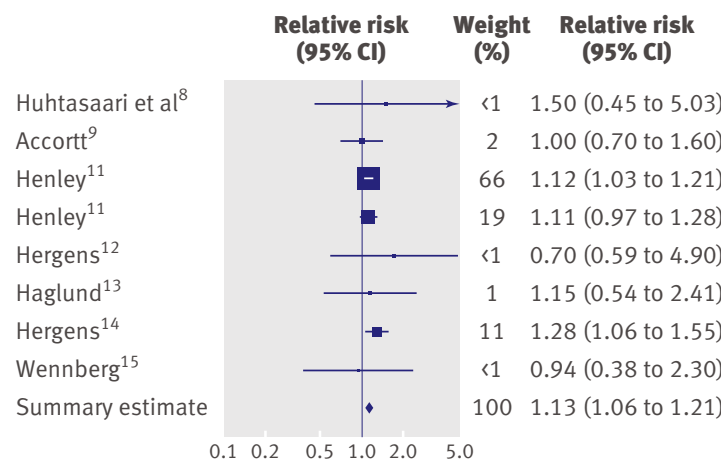

Fig 2 | Forest plot of risk estimates for fatal myocardial infarction among users of smokeless tobacco products

myocardial infarction attributable to use of smokeless tobacco products was $0.5 \%$ in the United States and $5.6 \%$ in Sweden. The corresponding figures for deaths from stroke were $1.7 \%$ and $5.4 \%$ : the latter result was based on a summary relative risk that was not statistically significant.

\section{DISCUSSION}

This meta-analysis showed an increased risk of fatal myocardial infarction and fatal stroke among users of smokeless tobacco products compared with non-users. Although the magnitude of the excess risk, particularly for fatal myocardial infarction, was small, the consistency of the results among studies and their robustness for study design and quality added to their credibility. The meta-analyses including the results on non-fatal cardiovascular diseases, however, showed heterogeneity between studies, which limits their interpretation. All the studies on risk of non-fatal myocardial infarction and stroke were done in Sweden. Several possible explanations may be given for the discrepancies in results between fatal and non-fatal cardiovascular diseases. Outcomes are less likely to be misclassified in studies of incident cases recruited in hospital shortly after diagnosis. It is unclear, however, how misclassification of fatal cardiovascular diseases could generate a false positive result in prospective studies, as misclassification would most likely be non-differential for use of smokeless tobacco. ${ }^{24}$ The difference in results might, however, reflect a true phenomenon.

Animal experiments and studies in humans indicate that smokeless tobacco has mainly short term effects

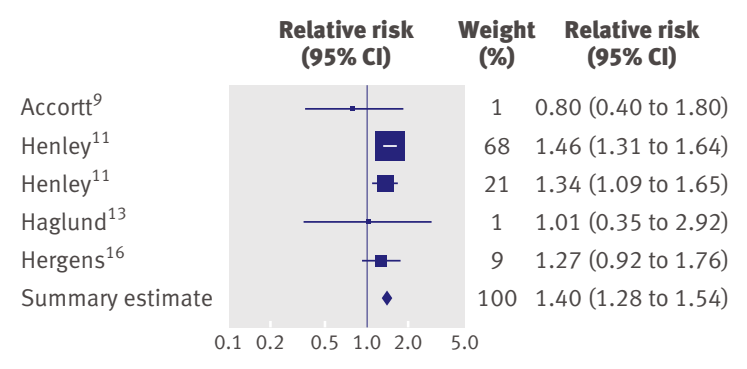

Fig 3 | Forest plot of risk estimates for fatal stroke among users of smokeless tobacco products 
Table $3 \mid$ Attributable fraction and attributable number of deaths from myocardial infarction and stroke among men in United States and Sweden

\begin{tabular}{lcc} 
Country (year) and outcome & $\begin{array}{c}\text { Attributable } \\
\text { fraction (\%) }\end{array}$ & No of deaths \\
United States (2000): & & \\
\hline Fatal myocardial infarction & 0.5 & 483 \\
\hline Fatal stroke & 1.7 & 1093 \\
\hline Sweden (2001): & & \\
\hline Fatal myocardial infarction & 5.6 & 346 \\
\hline Fatal stroke & 5.4 & 220
\end{tabular}

Based on mortality data from WHO database, ${ }^{23} 4.4 \%$ prevalence of use in United States, ${ }^{21}$ and $23 \%$ prevalence of use in Sweden, ${ }^{22}$ and country specific relative risks from table 2 .

resulting in increased blood pressure and heart rate that are presumably due to nicotine, whereas data on long term use and hypertension are inconclusive. ${ }^{34}$ Several studies suggest that increased levels of triglycerides, diabetes, obesity, and metabolic syndrome might be associated with use of smokeless tobacco. ${ }^{14}$ Experimental findings of increased damage to the cardiac muscle and poorer myocardial healing in dogs exposed to nicotine may provide a pathophysiological rationale for the increased mortality from myocardial infarction. Furthermore, nicotine induced cardiac arrhythmias in dogs and increased the sensitivity towards arrhythmias and induced ventricular fibrillation in canine hearts that survived myocardial infarction. ${ }^{4}$

Previous reviews on the risk of cardiovascular diseases among users of smokeless tobacco emphasised the differences in exposure and results and concluded that the evidence did not suggest an association. ${ }^{3525}$ Our meta-analysis, however, is based on explicit criteria for inclusion of studies, and abstraction and pooling of results. Compared with the most recent published meta-analysis, ${ }^{5}$ our review excluded two studies that have been included in subsequent publications ${ }^{\mathrm{w} 176 \mathrm{w} 183}$ and one study with no risk estimate for never smokers, ${ }^{\text {w73 }}$ and included four studies published in the past two years. ${ }^{13-16}$ Our meta-analysis provides consistent evidence of a moderate increase in risk of fatal myocardial infarction and fatal stroke, whereas it does not provide evidence of a difference in effect of products consumed in North America compared with northern Europe. The different conclusions reached by previous authors might be explained by the combination of results on incident and fatal cardiovascular diseases, the lack of inclusion of several recent studies, and the lack of a formal meta-analysis. ${ }^{3525}$

The results on fatal myocardial infarction did not depend on the inclusion of case-control studies, and all risk estimates for fatal stroke were based on prospective studies. Cohort studies might be prone to bias if the members change their use of smokeless tobacco products during follow-up. This would, however, generate a positive result for smokeless tobacco only if users switched to smoking products. Some evidence from the United States shows that use of smokeless tobacco may lead to subsequent cigarette smoking. ${ }^{26}$ The Swedish data do not support the hypothesis that smokeless tobacco is a precursor to future smoking. ${ }^{2728}$ Other sources of bias (for example, misclassification of outcomes) in cohort studies are unlikely to result in a false positive result. This is not the case for case-control studies, in which information bias remains a potential problem. ${ }^{24}$ The consistency of results in prospective and retrospective studies, however, argues against such bias playing an important part.

Confounding by active smoking is a potential source of bias in the studies included in the meta-analysis. We aimed to control for this by restricting the meta-analysis to studies of never smokers. Only two relatively small case-control studies included former smokers in their category of non-smokers. ${ }^{78}$ It is plausible, however, that some current or former smokers might have been misclassified as never smokers. If this happened, irrespective of smokeless tobacco use, it would have resulted in bias towards the null. However, the possibility remains that confounding owing to misclassification of smoking status might have been differential for smokeless tobacco use (that is, smokeless tobacco users might have comprised more misclassified smokers than non-users), thus resulting in an inflation of the risk associated with smokeless tobacco use. A sensitivity analysis carried out by us showed that to explain a relative risk of 1.40 for fatal stroke reported in this study $25 \%$ of smokeless tobacco users should actually be misclassified as smokers (assuming no effect of smokeless tobacco, relative risk equal to 2.5 for tobacco smoking, and no misclassification among non-users). Such a degree of misclassification is unlikely. The results included in the meta-analysis were adjusted for sex, age, race (if appropriate), and (in cohort studies) for other known risk factors of cardiovascular disease, such as body mass index and hypertension.

In conclusion, in studies carried out in the United States and Sweden we detected an association between use of smokeless tobacco products and risk of fatal myocardial infarction and fatal stroke, which is not readily explained by chance. Confounding and other sources of bias, however, cannot be completely excluded on the basis of available data, although we found no strong evidence for their effect. If the association is real, its public health and clinical implications might be substantial, despite the fact that the

\section{WHAT IS ALREADY KNOWN ON THIS TOPIC}

Smokeless tobacco products are widely used in many populations

An association with risk of cardiovascular disease is plausible

\section{WHAT THIS STUDY ADDS}

This systematic review and meta-analysis provided evidence for an association between use of smokeless products and risk of fatal myocardial infarction and stroke 
magnitude of the excess risk is small. Future research should aim to clarify the mechanisms of effect of smokeless tobacco products on deaths from cardiovascular disease and to elucidate whether a similar effect is present for non-fatal myocardial infarction and non-fatal stroke.

We thank Sharon Grant, International Agency for Research on Cancer, for help with the literature search

Contributors: Both authors had full access to all of the data in the study and are jointly responsible for the integrity of the data and the accuracy of the data analysis.

Funding: This study received no funding.

Competing interests: None declared.

Ethical approval: Not required.

1 International Agency for Research on Cancer. IARC monographs on the evaluation of carcinogenic risks to humans. Vol 89. Smokeless tobacco products. Lyon: IARC, 2008.

2 Rodu B, Godshall WT. Tobacco harm reduction: an alternative cessation strategy for inveterate smokers. Harm Reduct / 2006;3:37.

3 Broadstock $M$. Systematic review of the health effects of modified smokeless tobacco products. NZHTA Report 2007;10:1-129.

4 SCENIHR (Scientific Committee on Emerging and Newly-Identified Health Risks). Scientific opinion on the health effects of smokeless tobacco products. Brussels: European Commission, 2008. http://ec europa.eu/health/ph_risk/committees/04_scenihr/docs/ scenihr o 013.pdf.

5 Lee PN. Circulatory disease and smokeless tobacco in Western populations: a review of the evidence. Int J Epidemiol 2007,36:789-804.

6 Stroup DF, Berlin JA, Morton SC, Olkin I, Williamson GD, Rennie D, et al. Meta-analysis of observational studies in epidemiology. A proposal for reporting. JAMA 2000;283:2008-12.

7 Huhtasaari F, Asplund K, Lundberg V, Stegmayr B, Wester PO. Tobacco and myocardial infarction: is snuff less dangerous than cigarettes? BMJ 1992;305:1252-6.

8 Huhtasaari F, Lundberg V, Eliasson M, Janlert U, Asplund K. Smokeless tobacco as possible risk factor for myocardial infarction: a population-based study in middle-aged men. J Am Coll Cardiol 1999;34:1784-90.

9 Accortt NA, Waterbor JW, Beai C, Howard G. Chronic disease mortality in a cohort of smokeless tobacco users. Am J Epidemiol 2002;156:730-7.

10 Asplund K, Nasic S, Janlert U, Stegmayr B. Smokeless tobacco as a possible risk factor for stroke in men. A nested case-control study. Stroke 2003;34:1754-9.
11 Henley SJ, Thun MJ, Connell C, Calle EE. Two large prospective studies of mortality among men who use snuff or chewing tobacco. Cancer Causes Control 2005;16:347-58.

12 Hergens MP, Ahlbom A, Andersson T, Pershagen G. Swedish moist snuff and myocardial infarction among men. Epidemiol 2005;16:12-6.

13 Haglund B, Eliasson M, Stenbeck M, Rosén M. Is moist snuff use associated with excess risk of IHD or stroke? A longitudinal follow-up of snuff users in Sweden. Scan J Publ Health 2007;35:618-22.

14 Hergens MP, Alfredsson L, Bolinder G, Lambe M, Pershagen G, Ye W. Long-term use of Swedish moist snuff and the risk of myocardial infarction among men. J Intern Med 2007;262:351-9.

15 Wennberg P, Eliasson M, Hallmans G, Johansson L, Booman K, Jansson JH. The risk of myocardial infarction and sudden cardiac death amongst snuff users with or without a previous history of smoking. J Intern Med 2007;262:360-7.

16 Hergens MP, Lambe M, Pershagen G, Terent A, Ye W. Use of smokeless tobacco and the risk of stroke among Swedish men. Epidemiol 2008;19:794-9.

17 DerSimonian R, Laird N. Meta-analysis in clinical trials. Control Clin Trials 1986;7:177-88.

18 StataCorp LP. Intercooled Stata 9.1 for Windows. College Station, TX StataCorp, 2005.

19 Begg CB, Mazumdar M. Operating characteristics of a rank correlation test for publication bias. Biometrics 1994;50:1088-101.

20 Greenland S, O’Rourke K. Meta-analysis. In: Rothman KJ, Greenland S, Lash TL, eds. Modern epidemiology, 3rd edn. Philadelphia, Pa: Lippincott Williams \& Wilkins, 2008:652-82.

21 Giovino GA, Schooley MW, Zhu BP, Chrismon JH, Tomar SL, Peddicord JP, et al. Surveillance for selected tobacco-use behaviors -United States, 1900-1994. MMWR CDC Surveill Summ 1994;43:1-43.

22 Folkhälsa. Lägesrapport 2005. Stockholm: Socialstyrelsen, 2006:24 www.socialstyrelsen.se/Publicerat/2006/9081/2006-131-7.htm.

23 World Health Organization. Mortality database. Geneva: WHO, 2008. www.who.int/healthinfo/morttables/en/index.html.

24 Rothman KJ, Greenland S. Precision and validity in epidemiologic studies. In: Rothman KJ, Greenland S, eds. Modern epidemiology, 2nd edn. Philadelphia, PA: Lippincott-Raven, 1998:115-34.

25 Critchley JA, Unal B. Is smokeless tobacco a risk factor for coronary heart disease? A systematic review of epidemiological studies. Eur Cardiovasc Prev Rehabil 2004;11:101-12.

26 Tomar SL. Is use of smokeless tobacco a risk factor for cigarett smoking? The U.S. experience. Nicotine Tob Res 2003;5:561-9.

27 Rodu B, Stegmayr B, Nasic S, Asplund K. Impact of smokeless tobacco use on smoking in northern Sweden. J Intern Med 2002;252:398-404.

28 Stegmayr B, Eliasson M, Rodu B. The decline of smoking in northern Sweden. Scand I Public Health 2005;33:321-4.

Accepted: 30 March 2009 